\title{
CORRIGENDUM
}

\section{MACKEY CONVERGENCE AND QUASI-SEQUENTIALLY WEBBED SPACES}

THOMAS E. GILSDORF

\author{
Department of Mathematics \\ University of North Dakota \\ Grand Forks, ND 58202
}

The following were not discovered in time to correct before the publication of the above named paper [Int. Jour. Math. \& Math. Sci., 14, no.1, 1991, pp. 17-26].

1. Definition 3.3, page 21 is incorrectly stated. It should read: A Hausdorff locally convex space $E$ is locally Baire if for each bounded subset $A \subset E$ there is a bounded disk $B \subset E$ such that $A \subset B$ and $E_{B}$ is a Baire space.

2. The proof of the $(b) \Rightarrow(c)$ part of Theorem 3.4, page 23 is in error. The following is the correct proof:

Let $x_{n} \rightarrow 0$ in $E$. Then $x_{n} \rightarrow 0$ in $E_{K}$ for some compact disk $K \subset E$. If $A$ denotes the $E_{K^{-}}$ closure of convbal\{ $\left\{x_{n}: n \in N\right\}$, and $B$ is the $E$-closure of convbal $\left\{x_{n}: n \in \mathbf{N}\right\}$, then we have that $A$ is compact in $E_{\boldsymbol{K}}$ and id: $E_{\boldsymbol{K}} \rightarrow E$ is continuous, making $A$ compact in $E$. Clearly, convbal $\left\{x_{n}: n \in \mathbb{N}\right\} \subset A$, so $B \subset A$; hence, $B$ is compact in $E$, and 5.1.11, page 153 of PérezCarreras and Bonet (reference [9] in the paper) applies.

The author apologizes for these errors and any confusion they may have caused. 


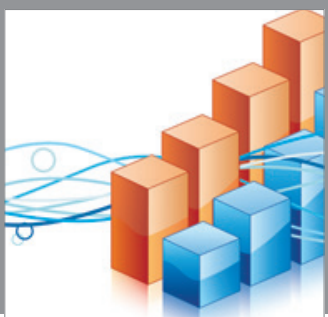

Advances in

Operations Research

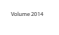

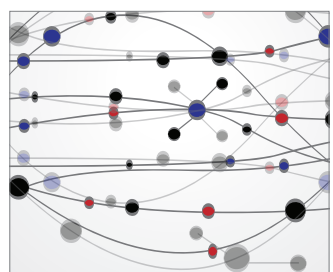

\section{The Scientific} World Journal
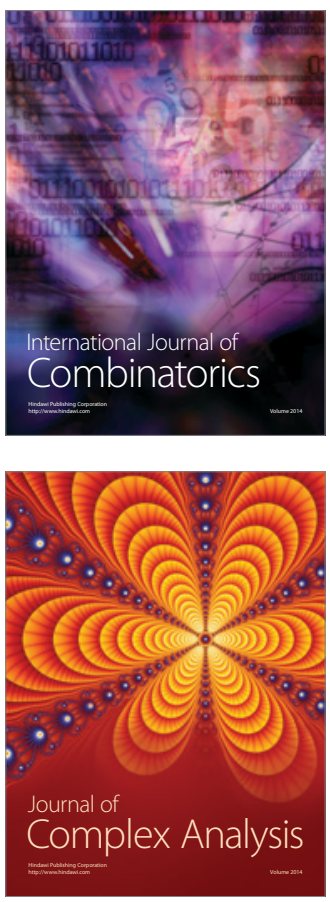

International Journal of

Mathematics and

Mathematical

Sciences
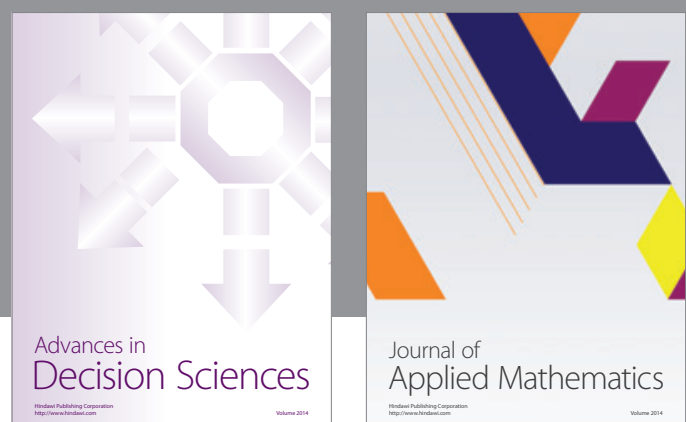

Journal of

Applied Mathematics
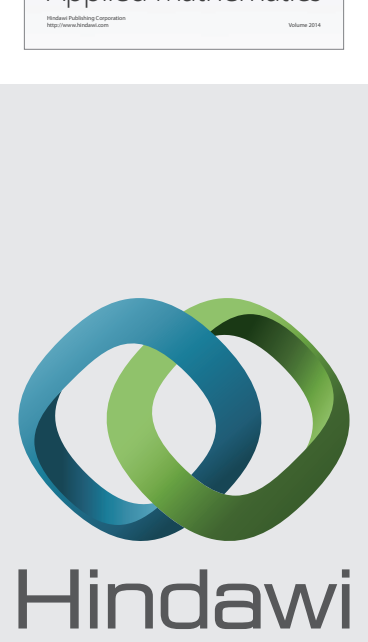

Submit your manuscripts at http://www.hindawi.com
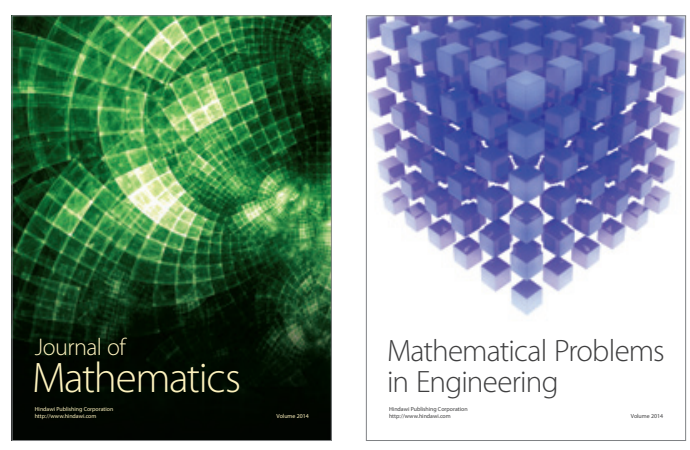

Mathematical Problems in Engineering
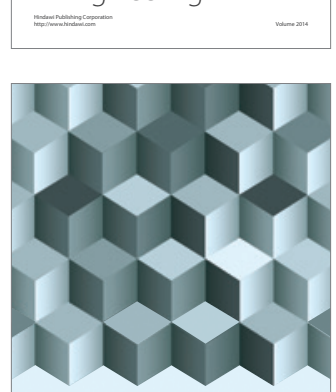

Journal of

Function Spaces
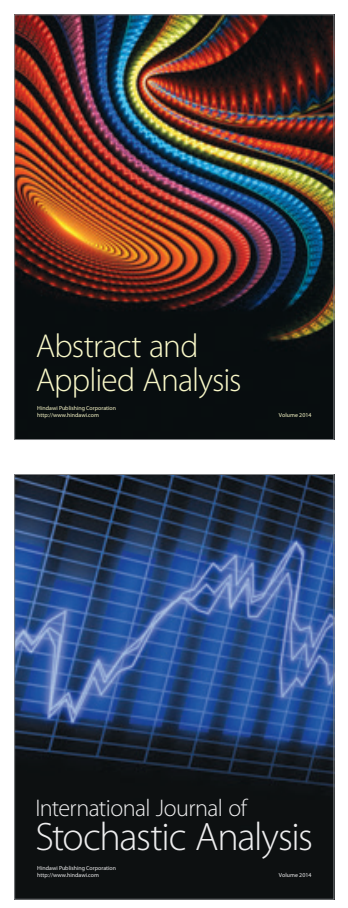

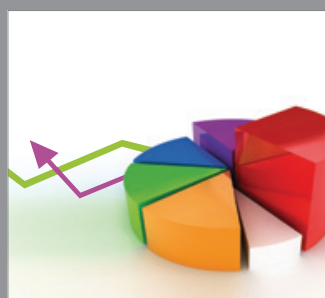

ournal of

Probability and Statistics

Promensencen
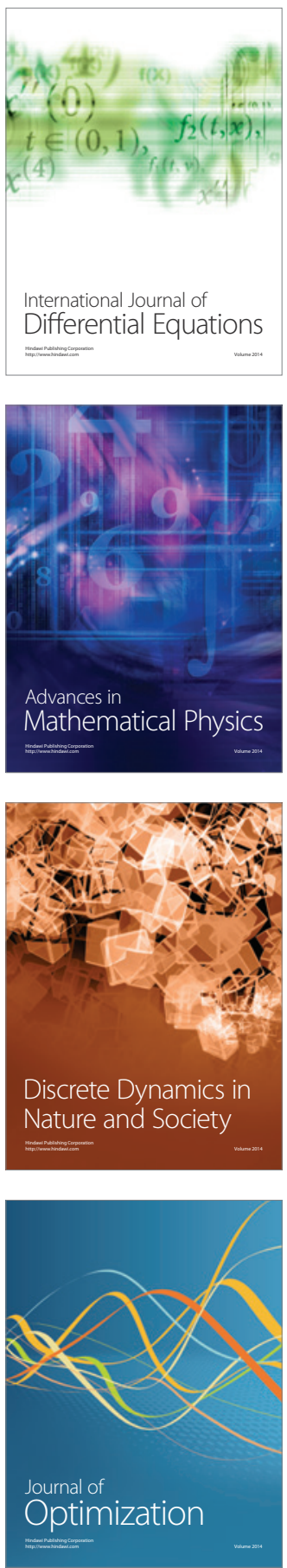